\title{
A COMUNICAÇÃO DO PCN BRASIL: COMO AS ESTRATÉGIAS E OS INSTRUMENTOS DE COMUNICAÇÃO PODEM CONTRIBUIR PARA 0 AUMENTO DA EFICÁCIA DA AGÊNCIA?'
}

Luíza Mônica Assis da Silva²

\section{SINOPSE}

Este artigo tem como objetivo verificar se os requisitos relativos aos indicadores sobre comunicações, definidos pela Organização para a Cooperação e Desenvolvimento Econômico (OCDE) no âmbito das Diretrizes sobre Conduta Empresarial Responsável de Empresas Multinacionais, são atendidos pelo Ponto de Contato Nacional brasileiro (PCN Brasil) e analisar qualitativamente os Instrumentos de Comunicação Institucional (ICls) com vistas ao aprimoramento dos processos comunicacionais da agência. 0 referencial teórico utilizado é o da comunicação organizacional integrada, com destaque para a importância do papel dos instrumentos de comunicação pública nos processos comunicacionais. Adota-se uma metodologia qualitativa e observacional para exame dos ICls presentes na página do PCN Brasil: site, textos oficiais sobre as Diretrizes, vídeo, Manual de Procedimentos para Instâncias Específicas e relatórios. Os resultados indicam que a agência cumpre a maioria dos quesitos obrigatórios e recomendados pela OCDE. Entretanto, percebe-se a ausência de planejamento estratégico e integrado direcionado aos diferentes públicos e partes interessadas. Conclui-se que é necessário definir uma política de comunicação; dar maior autonomia à equipe técnica do PCN Brasil; aprimorar e avaliar os instrumentos de comunicação, em especial a arquitetura de informação do site; e aumentar a sinergia com as áreas de comunicação e tecnologia da informação do Ministério da Economia. Além disso, deve-se reforçar o entendimento comum do mandato do PCN Brasil junto às agências interministeriais, outros setores governamentais e partes interessadas.

Palavras-chave: Ponto de Contato Nacional; PCN Brasil; OCDE; conduta empresarial responsável; comunicação; instrumentos de comunicação; comunicação organizacional.

\begin{abstract}
The aim of this study is to check the accomplishment, by the Brazilian National Contact Point (NCP-Brazil), of the requirements related to communications indicators established by the Organisation for Economic Cooperation and Development (OECD), within the Guidelines for Responsible Business Conduct, and analyse qualitatively the Institutional Communicational Instruments (ICls), aiming at the improvement of the communicational processes of the organization. The integrated organizational communication, which emphasizes the importance of the role of mechanisms of public communication in organizational communication processes, is the theoretical background of the study, which exams NCP-Brazil's ICls, including websites, documents concerning the Guidelines, videos, Tutorial of Procedures for Specific Instances and official reports. The results indicate that the organization accomplishes most of the OECD's mandatory requisites and recommendations. However, the absence of strategic and integrated planning focused on different audiences and potential interested ones is noted. Thus, there is a need to define a communication policy; give higher autonomy to NCP-Brazil's technical staff; improve and evaluate the communication tools, particularly the website's architecture of information; and enhance the synergy with the Ministry of Economy's areas of communication and information technology. In addition, it is crucial to reinforce the common understanding of NCP-Brazil's mandate before critical bodies of the Federal Government as well as other stakeholders.
\end{abstract}

\footnotetext{
1. Este artigo foi financiado com recursos da Comissão Econômica para a América Latina e o Caribe (Cepal).
}

2. Doutora em psicologia social do trabalho e das organizações pela Universidade de Brasília (UnB) e mestre em Ciência Política pela UnB; docente e pesquisadora nas áreas de processos comunicacionais nas organizações e responsabilidade social das empresas; consultora de comunicação organizacional. 
Keywords: National Contact Point; NCP-Brazil; OECD; responsible business conduct; communication; mechanisms of communication; organizational communication.

JEL: F53; M14.

Artigo recebido em 16/4/2021 e aprovado em 26/4/2021.

DOI: http://dx.doi.org/10.38116/bepi29art3

\section{INTRODUÇÃO}

Os países que postulam ser membro da Organização para a Cooperação e Desenvolvimento Econômico (OCDE), como é o caso do Brasil, devem cumprir uma série de requisitos e, entre eles, está a adesão às Diretrizes para Empresas Multinacionais, ${ }^{3}$ que estão diretamente ligadas ao campo da Conduta Empresarial Responsável (CER) e da responsabilidade socioambiental das empresas. O documento oficial da OCDE, traduzido pelo PCN Brasil, que institui as Diretrizes as define como:

recomendaçóes dirigidas pelos Governos às empresas multinacionais. As Diretrizes visam assegurar que as operaçóes dessas empresas estejam em harmonia com as políticas governamentais, fortalecer a base da confiança mútua entre as empresas e as sociedades onde operam, ajudar a melhorar o clima do investimento estrangeiro e aumentar a contribuição das empresas multinacionais para o desenvolvimento sustentável. As Diretrizes são parte integrante da Declaração da OCDE sobre Investimento Internacional e Empresas Multinacionais, cujos outros elementos são relacionados a tratamento nacional, obrigaçóes conflitantes impostas às empresas e incentivos e desincentivos ao investimento internacional. As Diretrizes fornecem princípios e padróes voluntários para uma conduta empresarial consistente com as leis adotadas e os padrôes reconhecidos internacionalmente. No entanto, os países aderentes às Diretrizes assumem um compromisso vinculante em implementá-las em conformidade com a decisão do Conselho da OCDE sobre as Diretrizes da OCDE para as Empresas Multinacionais. Além disso, as questóes abrangidas pelas Diretrizes também podem ser objeto de legislação nacional e compromissos internacionais. ${ }^{4}$

As Diretrizes tratam de: i) conceitos e princípios; ii) políticas gerais; iii) transparência; iv) direitos humanos; v) relaçôes laborais; vi) meio ambiente; vii) combate à corrupção, à solicitação de suborno e à extorsão; viii) interesses do consumidor; ix) concorrência; e ix) tributação. São o "único código de conduta empresarial responsável acordado multilateralmente e que os governos se comprometeram a promover". ${ }^{5}$ São recomendações, ${ }^{6}$ mecanismos de soft law e tiveram sua última revisão em 2011.

Todos os 49 países aderentes, que incluem membros e não membros da OCDE, foram instados a criar as figuras dos Pontos de Contato Nacional (PCNs), que hoje atuam em mais de cem países e territórios. Sua missão é disseminar as Diretrizes junto às partes interessadas, operacionalizá-las e denunciar sua violação propondo mecanismos extrajudiciais de mediaçáo, bem como alternativas consensuais entre as partes para reparação de danos. Além disso, o trabalho dos PCNs visa contribuir

3. Doravante denominadas Diretrizes. Disponíveis em: <https://www.gov.br/produtividade-e-comercio-exterior/pt-br/assuntos/camex/pcn/ diretrizes-da-ocde-para-empresas-multinacionais $>$.

4. Disponível em: <https://www.gov.br/produtividade-e-comercio-exterior/pt-br/assuntos/camex/pcn/diretrizes-da-ocde-para-empresas-multinacionais>. 5. Disponível em: <http://mneguidelines.oecd.org/2018-Annual-Report-MNE-Guidelines-EN.pdf>.

6. Isso significa que não têm a força de um mecanismo legal, mas buscam estimular a aplicação da conduta correta, ética e que contribua para o desenvolvimento sustentável global e possível remediação de danos por parte das corporações internacionais que operam nos países aderentes e/ou a partir deles. 
para a construçáo e disseminaçáo de programas de due diligence $e^{7}$ em diferentes setores da economia, como financeiro; extrativo mineral; de vestuário e calçados; e agricultura, assim como o combate ao trabalho infantil.

Nos últimos vinte anos, os PCNs constituíram um forte instrumento para a implementação das Diretrizes e promoção de práticas de CER, bem como tiveram seu trabalho interligado a várias agências das Naçóes Unidas voltadas para a sustentabilidade e para a promoção dos direitos humanos. ${ }^{8}$ As revisóes das Diretrizes ${ }^{9}$ e Procedimentos visaram, entre outros aspectos, a construção de capacidades e de melhoria de sua efetividade, transparência, visibilidade e prestaçáo de contas. Aspectos profundamente interligados e baseados em políticas e processos de comunicação capazes de promover uma comunicação efetiva com as partes interessadas, de modo a propiciar o alcance dos objetivos organizacionais.

O PCN Brasil foi instituído em 2003 e passou por um progresso significativo ao longo de seus dezoito anos. Destacamos, especialmente, as mudanças a partir de 2019 para que pudesse acompanhar as proposiçôes da última revisão das Diretrizes. Nesse ano, o modelo, de estrutura interministerial, teve sua capacidade ampliada para atuação nas diferentes áreas das Diretrizes, bem como foi elaborado o manual de procedimentos que padroniza e esclarece sobre o rito processual para as denúncias de violaçáo das Diretrizes. Houve também aumento de seus recursos técnicos e humanos.

O PCN Brasil figura em quarto lugar no número de casos recebidos de violação das Diretrizes, ao lado dos PCNs da França e da Alemanha (OCDE, 2020b). É o PCN que mais recebe alegaçóes na América Latina. A intensa demanda e relevância desse mecanismo requer, portanto, conhecer suas fraquezas e fortalecer suas capacidades institucionais. Pesquisas indicam que empresas que foram alvo de denúncias podem ter danos em sua reputação e imagem, bem como perda no valor de suas açóes no mercado. É com base nessa premissa que o trabalho dos PCNs é apresentado como capaz de impactar favoravelmente as empresas, ao propor alternativas de remediação para os danos e minimizar os riscos por meio de due diligences. Outra importante questão nesse contexto é que o comportamento socialmente responsável, promovido pelos PCNs, pode livrar as empresas de pesadas multas e indenizaçóes.

Quando as empresas cometem graves violaçóes das Diretrizes, em geral, os fatos que sobressaem na mídia são negativos e as medidas de remediação não ganham tanto destaque. Caso o papel do PCN seja reconhecido e visível pela sociedade, pode contribuir tanto para o aumento das denúncias,

7. Mecanismo da OCDE que tem como objetivo orientar e ajudar as empresas de diferentes setores econômicos a identificar, prevenir, diminuir, contabilizar e proceder diante de impactos adversos reais e potenciais. Os guias de due diligence (financeiro, mineração, vestuário e calçados etc.) foram elaborados de forma participativa com os stakeholders das áreas e apresentam explicações em linguagem simples, além de serem ilustrativos de cases que possibilitam as empresas a lidarem com questões adversas relativas aos trabalhadores, direitos humanos, meio ambiente, suborno, consumidores e governança corporativa, que podem estar associados tanto às suas operações diretas como à sua cadeia de fornecedores, bem como a outros tipos de relações comerciais. Disponível em: <https://www.oecd.org/investment/due-diligenceguidance-for-responsible-business-conduct.htm>.

8. Disponível em: <https://www.gov.br/produtividade-e-comercio-exterior/pt-br/assuntos/camex/pcn/diretrizes-da-ocde-para-empresas-multinacionais>. 9. Desde sua criação em 1976, aconteceram cinco revisões nos anos 1979, 1984, 1991, 2000 e 2011. Essas mudanças tiveram por objetivo esclarecer e ampliá-las com novos temas/capítulos, a saber: meio ambiente, direitos humanos, direito do consumidor, combate à corrupção e compromisso da cadeia de fornecedores com a CER. As revisões também propõem procedimentos para implementação das Diretrizes para lidar com denúncias de violações (instâncias específicas) e de due diligence. Os PCNs devem elaborar o Manual de Procedimentos para Instâncias Específicas e torná-lo disponível no site da agência, bem como criar uma base de informações com os status das denúncias, declarações e declarações finais sobre o caso. Este documento deve ser disponibilizado, preferencialmente, em inglês e no idioma nacional no site da agência. Também foi criada uma base de dados aberta e informada pelos PCNs para publicizar as informações sobre as denúncias recebidas no site da OCDE. 
quanto para a divulgação dos resultados positivos das alegações e contribuir para reduzir os danos à imagem empresarial. Entretanto, quando o mecanismo das instâncias específicas ${ }^{10}$ é pouco conhecido e não tem impacto na formação da opinião pública, podemos entender que a relação entre imagem e Conduta Empresarial Responsável (CER) só é percebida em um conjunto limitado e bem específico de empresas multinacionais, de grande porte e que dependem de grupos selecionados de acionistas, investidores e consumidores.

Hoje, a maioria das empresas denunciadas não aceita participar ou dar continuidade aos bons ofícios, etapa em que o PCN busca viabilizar um acordo de consenso entre as partes para resolução das questôes relativas a instâncias específicas. Nesse sentido, ter uma política de comunicação claramente definida, desenvolver campanhas de mobilização social em prol das Diretrizes, da CER e dos temas de due diligence são fundamentais para o cumprimento da missão do PCN.

Nos últimos anos, o mandato dos PCNs tem sido substancialmente ampliado, com as recomendaçóes de follow up dos acordos das declaraçóes finais e a missão de promover a CER junto a agências governamentais, empresas estatais e nas compras públicas. Dessa maneira, é fundamental que o PCN nacional seja percebido como credível, identificado como um importante ator na promoção da CER.

A comunicação nas organizações tem como principal função melhorar, de modo integrado, as relaçôes comunicativas que impactam a eficácia e a eficiência das organizaçóes junto aos seus públicos internos (funcionários de um setor e demais áreas) e diversificados públicos externos com os quais se relaciona. Além disso, colabora de modo essencial para a formação de uma imagem positiva, credibilidade e confiança de que as organizaçôes estão cumprindo a missão e desempenhando os papéis para os quais foram criadas, bem como para sua influência político-social (Kunsch, 2003).

Seguindo Duarte (2009), a análise dos instrumentos de comunicação institucionais (ICI) - sites, documentos públicos, eventos, cartazes, folders, fyers, bases de dados, clipping da imprensa, boletins de notícias, relatórios, discursos etc. - por meio dos quais as organizaçôes falam sobre si mesmas e sobre as açóes que desempenham é extremamente importante, uma vez que permite identificar e, por vezes, mensurar e auditar os aspectos de transparência, participaçáo, accountability, imagem e grau de confiança dos PCNs em sua missão de promover e zelar pelo cumprimento das Diretrizes. Tais instrumentos refletem também o grau de institucionalização de uma agência, sua trajetória de desenvolvimento, bem como a memória de suas atividades.

Os ICIs contribuem sobremaneira para a função de mobilização social para a causa da CER. Sua função maior é tornar os PCNs conhecidos e credíveis pelos stakeholders. Sáo veículos de disseminaçáo das Diretrizes, podendo propiciar o aumento da procura e o acompanhamento das alegaçóes de violaçáo.

Uma das formas de analisar a imagem e a identidade de uma organizaçáo é por meio das mensagens que veicula, uma vez que estas são importantes artefatos da cultura organizacional tangível e intangível. Pelos ICIs também podemos inferir e apreender a recepção dos conteúdos das mensagens

10. Na revisão das Diretrizes de 2000, ocorreu a definição de que os PCNs teriam em seu mandato um mecanismo não judicial para receber e mediar reclamações de violação da Diretrizes pelas empresas multinacionais, denominado alegação de inobservância ou instância específica. Desde então, essa é uma de suas principais funções, ou seja, receber e lidar com denúncias encaminhadas por indivíduos e/ou uma variedade de tipos de organizações (empresariais, representativas de empresas, sindicatos de trabalhadores, organizações não governamentais etc.), que são denominados alegantes, em contraposição às multinacionais denunciadas (alegadas). 
pelos públicos e se sua linguagem está adequada ao meio utilizado. ${ }^{11}$ As ferramentas da comunicação organizacional podem ser, portanto, fundamentais no engajamento das partes e compreensão do complexo de mediação e reparação e que requer um alto grau de compreensão e convencimento dos custos e benefícios das partes envolvidas. Nessa direção, estratégias comunicativas podem ser utilizadas no convencimento das empresas a participarem do processo sem o temor de danos reputacionais e confiança em sua confidencialidade, imparcialidade, isonomia, boa-fé, autonomia das partes e transparência. A comunicação institucional efetiva pode fazer com que as partes percebam que o principal papel do PCN é o de promover as Diretrizes e a CER em ambiente de negócios de mútua aprendizagem e corresponsabilidade entre os atores e não enxergar a agência como mais uma instância de sanção e punições às empresas denunciadas. Além disso, a comunicação estratégica e integrada pode dar publicidade e visibilidade ao processo de aprendizagem conjunta das partes nos processos e aos resultados dos acordos de mediação, bem como predispor as partes a compreender e aceitar um mecanismo extrajudicial, com menos formalidades e fundado na justiça restaurativa e na mediação de conflitos, ${ }^{12}$ propiciando que a resolução das denúncias ocorra de maneira dialogada e consensual entre as partes e náo no acirramento do conflito. ${ }^{13}$

O processo de mediação almejado pelos PCNs coloca as partes não numa relação de antítese, mas de solução de reparação conciliada, sustentável e baseada na comunicação, transparência, boa-fé e diálogo. Trata-se de um processo diferente das disputas judiciais tradicionalmente travadas pelas empresas com sindicatos, organizaçóes da sociedade civil e indivíduos quando elas causam danos sociais, ambientais e desrespeitam direitos individuais e coletivos. Nessa sistemática, estratégias comunicacionais eficazes podem vir a facilitar a promoção do diálogo e da compreensibilidade do processo, aumentando a adesão das partes (alegantes e alegadas) na busca de soluçóes e reduzir os prazos de resolução das alegaçóes.

Podemos inferir que o uso adequado de estratégias comunicativas poderia contribuir para minimizar um dos mais graves problemas do mecanismo: a falta de engajamento das companhias. De acordo com os dados informados pelos 49 PCNs em 2019, a porcentagem de instâncias específicas concluídas com acordo foi de apenas 33\%, sendo que 7\% das companhias aceitaram participar mas não chegaram a um acordo. A maioria das empresas denunciadas, $53 \%$, se recusaram a participar do processo e outros $7 \%$ chegaram a acordos em processos paralelos ao conduzido pelo PCN. Somente dois dos quinze casos concluídos em 2019 o foram no prazo de um ano previsto para a resoluçáo, sendo que um dos casos levou oito anos para ser finalizado (OECD, 2020a).

A análise dos ICIs e articulação com stakeholders estão previstas como elementos da revisão por pares (peer review) ${ }^{14}$ do PCN e reportada em seus relatórios como um dos elementos-chave de

11. Recomenda-se que as pesquisas de recepção sejam multimetodológicas e utilizadas outras técnicas como grupos focais, pesquisas de opinião junto aos públicos e análise de conteúdo das informações veiculadas pela mídia.

12. Trata-se do art. 2o da Lei no 13.140/2015, que dispõe sobre a mediação entre particulares como meio de solução de controvérsias e sobre a autocomposição de conflitos no âmbito da administração pública.

13. As medidas autorizativas de comunicação que a OCDE preconiza são: propor estratégias de comunicação e promocionais para disseminação das Diretrizes e mecanismos de due diligence; ter visibilidade, transparência e confiança dos stakeholders, bem como manter a confidencialidade quando se fizer necessário; reportar e prestar contas de suas atividades para seus governos e partes interessadas; e buscar e manter relacionamentos com as partes interessadas e parceiros estratégicos.

14. A revisão por pares é um processo bastante completo de avaliação a que todos os países-membros e aderentes devem se submeter até 2023. Os resultados das discussões e da revisão são apresentados em um relatório público nas bases de dados da OCDE, assim como as respostas dos PCNs dos países que foram objeto da revisão, caso desejem. 0 objetivo é verificar in loco e por meio da aprendizagem conjunta e da troca de experiências entre os pares se o PCN funciona de modo visível, acessível, transparente e responsável. Verifica-se também se as instâncias e procedimentos possibilitam lidar com as alegações de maneira imparcial, previsível, equitativa e compatível com as Diretrizes. 
avaliação e pontos a serem melhorados. A OECD Watch, organização não governamental (ONG) que representa a sociedade civil no acompanhamento das multinacionais, também avalia os PCNs com base em uma série de indicadores relacionados aos instrumentos de comunicação, entre outros. ${ }^{15}$

As estratégias, processos e instrumentos de comunicação contribuem sobremaneira para viabilizar os critérios nucleares do mandato dos PCNs - visibilidade, acessibilidade, transparência e accountability. Estão também diretamente ligados à promoção das Diretrizes junto às partes interessadas, e fazem parte da maioria dos elementos-chave que a OCDE considera para a análise do desempenho dos PCNs. ${ }^{16}$ Além disso, a análise dos processos comunicacionais (perspectivas e discursos das partes; e diálogo com stakeholders da equipe técnica e órgãos consultivos, seja na mídia, nas reunióes ou em encontros anuais) possibilita compreender e estabelecer diagnósticos precisos dos temas da revisão por pares, a saber: arranjos institucionais, promoção das Diretrizes e instância específicas.

Por ser um órgáo interministerial do governo brasileiro e estar sediado no Ministério da Economia, o PCN Brasil deve atender aos requisitos da comunicaçáo pública, especialmente à Lei de Acesso à Informação, ${ }^{17}$ paralelamente à garantia de confidencialidade. A comunicação pública tem, no caso do PCN, o papel de mediação estratégica entre as instituiçóes públicas, privadas, nacionais, internacionais, multilaterais, da sociedade civil e cidadãos. Seu pressuposto principal deve ser a transparência, a publicização e "deve ser pensada como um processo de interação no qual prevalecem a expressão, a interpretação e o diálogo" (Matos, 2011, p. 45).

Diante do exposto, podemos afirmar que o planejamento e uso estratégico e integrado da comunicação são fatores-chave para o desenvolvimento de alianças com os parceiros sociais, bem como para o desenvolvimento e manutenção das relações com os stakeholders (OECD, 2019) e a visibilidade e confiança no trabalho desenvolvido pelo PCN Brasil. Adicionalmente, lembramos que, com o advento dos meios e redes digitais, os instrumentos de comunicação foram potencializados de modo a atingir uma infinidade de públicos, além de serem caracterizados pela interação e dialogicidade, bem como de múltiplos recursos de linguagem.

Desse modo, o objetivo deste artigo é aferir, por meio de análises qualitativas, em que medida os ICIs do PCN Brasil estão em conformidade com os procedimentos vinculativos e autorizativos da OCDE e como a comunicação institucional pode ser incrementada de modo a promover uma maior visibilidade, acessibilidade, transparência e accountability das atividades da agência, bem como fortalecer a efetividade de suas açóes de promoção da CER.

\section{METODOLOGIA DE ANÁLISE DOS ICls}

Primeiramente, são apresentados os indicadores de comunicação do PCN Brasil extraídos da pesquisa Avaliações do PCN da OECD Watch. Na sequência, visando avaliar os ICIs do PCN Brasil, efetua-se análise documental qualitativa do conteúdo e design relativos aos documentos disponíveis no

\footnotetext{
15. Disponivel em: <https://www.oecdwatch.org/indicator/>.

16. Entre eles estão: site, regras de procedimento on-line, plano promocional e organização de eventos. Todos demandam uma estreita relação com assessorias de comunicação e atividades de interface com a comunicação organizacional, relações públicas, assessoria de imprensa, publicidade e marketing.

17. Lei Federal no 12.527/2011, que estabelece que as informações referentes à atividade do Estado são públicas, exceto aquelas expressas em legislação específica.
} 
site do PCN Brasil. ${ }^{18}$ Foram analisados os seguintes instrumentos: site, vídeo institucional, manual de procedimentos e relatórios anuais. Além disso, a pesquisa valeu-se de uma entrevista com um membro da equipe técnica do PCN Brasil, em dezembro de 2020, na qual a comunicação institucional foi um tópico destacado.

\section{RESULTADOS E DISCUSSÃO}

\subsection{Avaliação do PCN Brasil pela OECD Watch}

A pesquisa da OECD Watch avaliou 48 PCNs com base em um conjunto de quarenta indicadores-chave de desempenho sobre organizaçáo e governança; procedimentos de tratamento das alegaçôes de inobservância das Diretrizes; e comunicaçóes. Para fins desta pesquisa, nos detemos nos indicadores relativos às comunicaçôes.

O quadro 1 mostra os dezenove indicadores de comunicação, a avaliação da OCDE Watch em relação ao atendimento dos requisitos pelo Brasil e pelos $48 \mathrm{PCN}$ s avaliados na pesquisa. Observa-se que, em relação aos nove requisitos obrigatórios sobre as comunicaçóes, o PCN Brasil apenas não cumpre os que estấo relacionados a due diligence e apresentação das declaraçóes finais na página institucional. Sugerimos que o destaque sobre due diligence seja observado, uma vez que o Brasil tem recebido várias reclamaçóes em áreas cobertas pelos guias - que são fruto de um processo participativo entre as partes interessadas, governos, OCDE e têm reconhecida qualidade técnica. Lembramos que os setores econômicos que receberam o maior número de denúncias no Brasil são: setor manufatureiro (10); setor financeiro e de atividades de seguro (8); e mineração (7). Dessa maneira, tornar esses documentos mais acessíveis e inteligíveis poderia incentivar as empresas de diferentes portes que atuam nesses setores a estarem mais atentas aos riscos, prevenção de danos e temas de CER específicas para esses grupos.

Em relação às declaraçôes finais, o PCN Brasil tomou a decisão de publicar todas as alegaçóes concluídas como declaraçóes. Até o momento de encerramento da coleta de dados deste estudo, elas não estavam no site por problemas de migração de informaçốes que serão discutidos adiante.

Quanto aos indicadores recomendados, observamos que a agência precisa melhorar a divulgaçáo e os resultados dos eventos organizados e coorganizados, bem como ampliar a participação de todos os grupos das partes interessadas. A publicização do orçamento é uma questão mais complexa por tratar-se de uma agência interministerial, e os custos materiais e humanos do secretariado serem de responsabilidade do Ministério da Economia.

Os requisitos cumpridos parcialmente (3) referem-se à apresentação mais detalhada e abrangente das Diretrizes, das funçóes do PCN e dos eventos promocionais. Sáo tópicos relativamente simples de resolver, mas que dependem de mudanças na arquitetura do site, tradução de documentos e maior autonomia da equipe técnica para inserção e atualização de informaçôes. A seguir apresentamos os resultados das análises qualitativas dos ICIs do PCN Brasil. 
QUADRO 1

Avaliação dos indicadores de comunicação do PCN Brasil pela OECD Watch

\begin{tabular}{|c|c|c|c|c|}
\hline Indicador & Status de implementação & Obrigatório & Recomendado & $\begin{array}{l}\text { Número de PCNs que } \\
\text { atendem ao indicador }\end{array}$ \\
\hline 1.Informações de contato do PCN. & Sim. & $x$ & & 43 \\
\hline 2.Diretrizes na língua nacional e em inglês. & Sim. & $x$ & & 41 \\
\hline 3. Apresenta as funções do PCN. & $\begin{array}{l}\text { Parcial, }{ }^{1} \text { uma vez que descreve sinteticamente as } \\
\text { funções. Destaca o tratamento das reclamações, mas } \\
\text { não as ações de promoção das Diretrizes. }\end{array}$ & & $x$ & 40 \\
\hline 4. Instruções para preenchimento das reclamações. & Sim, ${ }^{1}$ estão disponíveis em inglês e português. & & $x$ & 38 \\
\hline $\begin{array}{l}\text { 5. Apresenta as regras de procedimento no idioma nacional } \\
\text { e em inglês. }\end{array}$ & Sim. ${ }^{1}$ & $x$ & & 33 \\
\hline 6. 0 site é multilíngue. & $\begin{array}{l}\text { Parcial, }{ }^{1} \text { os principais documentos em relação às } \\
\text { alegações estão traduzidos. }\end{array}$ & $\mathrm{x}$ & & 32 \\
\hline 7. Reporta as atividades ao governo e/ou parlamento. & Sim. & & $x$ & 30 \\
\hline 8. Descreve os eventos promocionais. & Parcial, ${ }^{1}$ mas apenas no relatório da OCDE. & & $x$ & 29 \\
\hline 9. Relatório anual submetido à OCDE e publicado no site. & Sim. & $x$ & & 27 \\
\hline 10. Desenvolveu materiais promocionais. & $\begin{array}{l}\text { Sim: }{ }^{1} \text { site, vídeo e material impresso (não estão } \\
\text { disponíveis na página). }\end{array}$ & $\mathrm{x}$ & & 26 \\
\hline $\begin{array}{l}\text { 11. Organizou e/ou coorganizou eventos promocionais com } \\
\text { todos os grupos das partes interessadas. }\end{array}$ & $\begin{array}{l}\text { Não. Organizou e coorganizou eventos, mas sem a } \\
\text { participação de todos os grupos de partes interessadas. }\end{array}$ & & $x$ & 29 \\
\hline 12. O site mostra todos os textos de due diligence da OCDE. & $\begin{array}{l}\text { Não, o link para a OCDE e a tradução para o português } \\
\text { não estão disponíveis. }\end{array}$ & $\mathrm{x}$ & & 25 \\
\hline $\begin{array}{l}\text { 13. Realização de atividades no exterior para promoção } \\
\text { das Diretrizes. }\end{array}$ & $\begin{array}{l}\text { Sim, as atividades são descritas nos relatórios } \\
\text { submetidos à OCDE. }\end{array}$ & & $x$ & 24 \\
\hline $\begin{array}{l}\text { 14. } 0 \text { site mostra uma declaração final abrangente para cada } \\
\text { alegação que chega a esta fase. }\end{array}$ & $\begin{array}{l}\text { Não,' são apresentados apenas os resumos das } \\
\text { instâncias específicas. }\end{array}$ & $x$ & & 24 \\
\hline 15. Possui banco de dados de reclamações publicado no site. & Sim. & & $x$ & 23 \\
\hline 16.0 site mostra uma explicação abrangente das Diretrizes. & $\begin{array}{l}\text { Parcial, }{ }^{1} \text { o documento sobre as Diretrizes está disponível } \\
\text { em inglês e português (breve explicação). Também } \\
\text { foram criados folhetos e vídeo. }\end{array}$ & & $x$ & 20 \\
\hline 17. Apresenta as avaliações iniciais. & Sim. ${ }^{1}$ & $x$ & & 6 \\
\hline 18. Divulga o plano promocional delineando atividades futuras. & Não. & & $x$ & 6 \\
\hline 19. O site informa o orçamento e fluxos de gastos do PCN. & Não. & & $x$ & 2 \\
\hline
\end{tabular}

Fonte: OECD Watch. Disponivel em: <https://www.oecdwatch.org/indicator/>.

Elaboração da autora.

Nota: ${ }^{1}$ Indicadores revistos e atualizados pela autora, com base na observação da página do PCN Brasil no período de dezembro de 2020 a março de 2021.

\subsubsection{Site}

Os portais e sites da internet são parte das tecnologias digitais de informação e comunicação, uma forma de transmissão em rede que tem como características principais possibilidade de interatividade e diversidade de elementos numa mesma mensagem (textos, imagens, sons e recursos de hipermídia). Os sites institucionais têm a função de apresentar instituições para seus diversos públicos, fazendo uso da arquitetura da informação, design e conteúdo como ferramentas de informação e comunicação (Côrrea, 2008). A página do PCN Brasil é a principal ferramenta de acesso a informaçóes sobre o órgão e para apresentação de alegaçóes de inobservância das Diretrizes. Encontra-se no portal do governo federal, mais precisamente no Ministério da Economia, na seçáo relacionada à Câmara de Comércio Exterior (CAMEX).

As palavras-chave utilizadas para acesso à página devem ser Ponto de Contato Nacional ou PCN Brasil, do contrário, aparecem informaçôes sobre os Parâmetros Curriculares Nacionais, termo mais conhecido, porém da área de educação. A página apresenta alta velocidade de carregamento 
(até cinco segundos). O site adota o padrão do governo federal e não é atualizado diretamente pela equipe do PCN. O design apresenta boa tipologia, a cor predominante é o cinza e o destaque colorido é dado ao logotipo do governo federal, com as cores do país. Não apresenta gráficos ou ilustraçôes. A navegação é intuitiva e simples, por meio da barra de rolagem. Existe também um mecanismo de busca no site (figura 1).

\title{
FIGURA 1
}

\section{Printscreen da página inicial do PCN Brasil}

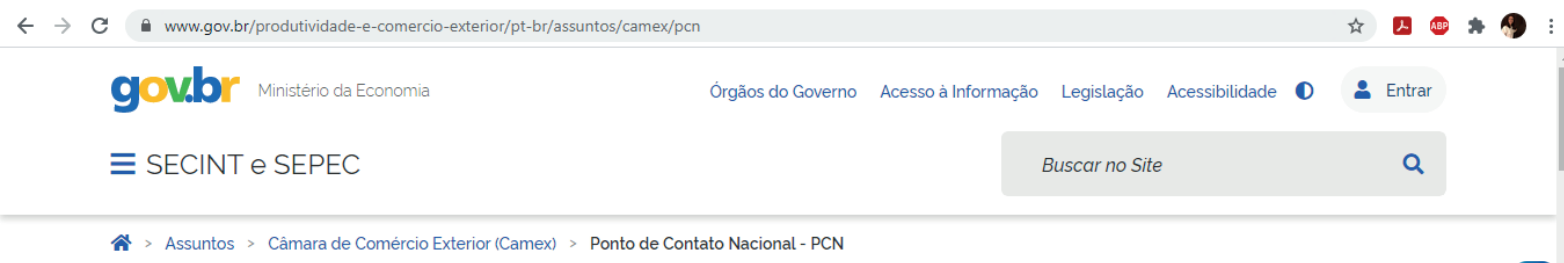

\section{Ponto de Contato Nacional Brasil - PCN}

\author{
Coronavirus (COVID-19)
}

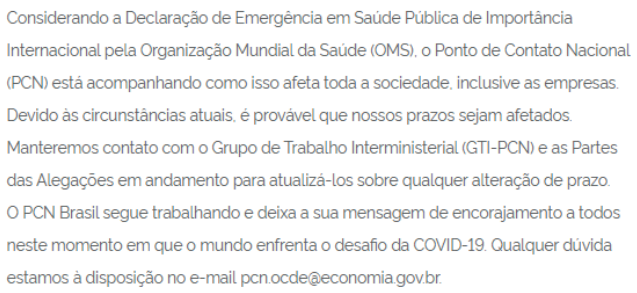

Considerando a Declaração de Emergència em Saúde Pública de Importância Internacional pela Organização Mundial da Saúde (OMS). o Ponto de Contato Nacional (PCN) está acompanhando como isso afeta toda a sociedade. inclusive as empresas Devido às circunstảncias atuais, è provável que nossos prazos sejam afetados Manteremos contato com o Grupo de Trabalho Interministerial (GTI-PCN) e as Partes das Alegaçōes em andamento para atualizá-los sobre qualquer alteração de prazo. O PCN Brasil segue trabalhando e deixa a sua mensagem de encorajamento a todos neste momento em que o mundo enfrenta o desafio da COVID-19. Qualquer dúvida estamos à disposição no e-mail pcn.ocde@economiagovibr

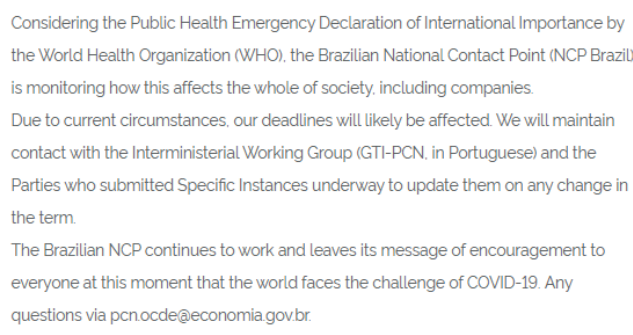

Considering the Public Health Emergency Declaration of International Importance by the World Health Organization (WHO), the Brazilian National Contact Point (NCP Brazil is monitoring how this affects the whole of society. including companies. Due to current circumstances, our deadlines will likely be affected. We will maintain contact with the Interministerial Working Group (GTI-PCN. in Portuguese) and the Parties who submitted Specific Instances underway to update them on any change in the term

The Brazilian NCP continues to work and leaves its message of encouragement to everyone at this moment that the world faces the challenge of COVID-19. Any questions via pcnocde@economiagovbr

Fonte: PCN Brasil.

O site não faz uso de recursos de hipermídia além do vídeo, e muitos links e botóes de acesso a documentos importantes não funcionam, entre os quais vale citar o relatório de encerramento e o processo de consulta pública do manual de procedimentos. Os botóes de consultar as alegaçóes de inobservância já recebidas pelo PCN, entenda o processo de devida diligência da OCDE e confira a lista de PCNs pelo mundo também não funcionam. Caso alguém clique neles, aparece o aviso indicado na figura 2.

O link da página relativo à $\mathrm{OCDE}$ remete à página elaborada pelo Ministério da Economia, com poucos recursos de hipermídia e sem conexão com a página dedicada ao Brasil no portal da $\mathrm{OCDE}^{19}$ e tampouco ao site oficial da organização. ${ }^{20}$ Temos, nesse sentido, os mesmos links em duplicidade, sem hierarquia de informaçôes e pouca utilização de recursos de hipermídia. Não há destaque para a relevância da observação das Diretrizes para acesso como membro à OCDE. A estrutura lógica da apresentação das informaçóes também poderia ser melhorada, de modo a tornar mais claras as funçóes e prerrogativas do órgáo, tais como due diligence, atividades promocionais e projetos especiais em CER.

19. Disponível em: <https://www.oecd.org/latin-america/countries/brazil/brasil.htm\#: :text> .

20. Disponível em: <https://www.oecd.org/>. 


\section{FIGURA 2}

Resultado dos links e botões que não remetem aos documentos indicados, especialmente os links dos relatórios das alegações

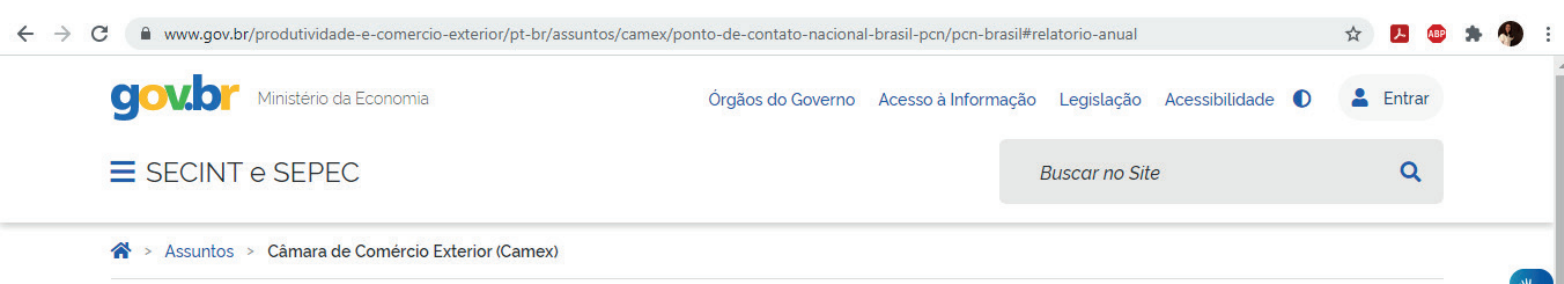

Desculpe, mas esta página não existe...

Pedimos desculpas pelo inconveniente, mas a página que vocè estava tentando acessar não existe neste endereço.

Se vocè está certo que o endereço informado está correto mas está encontrando um erro, por favor contate a Administraçāo do Site.

Obrigado.

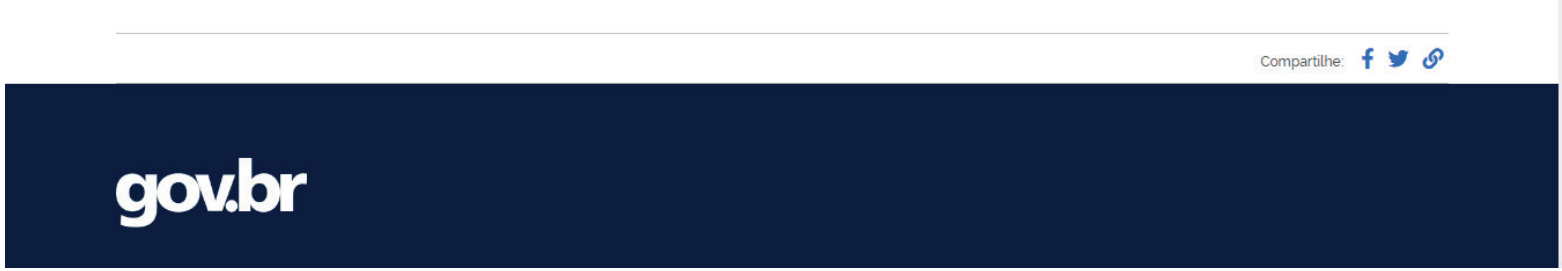

Fonte: PCN Brasil.

O site não apresenta seção de notícias ou de divulgação de eventos e de contato com a imprensa. Não há destaque para os eventos do PCN Brasil, em rede e com a OCDE. Inexistem informaçóes sobre o projeto desenvolvido em conjunto com a América Latina e Caribe em CER. Quando uma alegação é concluída, essa informação também não aparece na página. Informaçôes interessantes presentes nos relatórios do Comitê Nacional de Investimento (Coninv) não estão disponíveis de modo a atrair a imprensa e gerar notícias sobre o PCN, além de informar o público interessado. Note-se que uma seção de notícias no site contemplando estas pautas faria com que o PCN Brasil atendesse aos indicadores referentes à divulgação de açôes promocionais e de eventos organizados e coorganizados pela agência para a promoção das Diretrizes e de instrumentos de due diligence.

O quadro 2 mostra os critérios adotados para a análise qualitativa do site. Eles foram definidos com base em Correa (2008) e navegação cuidadosa da página por dois especialistas em comunicação organizacional da área de jornalismo e relaçóes públicas. 
QUADRO 2

Análise qualitativa do site do PCN Brasil

\begin{tabular}{|c|c|}
\hline Critério & Avaliação \\
\hline 1. Fonte de acesso ao site. & Acesso fácil por meio da ferramenta de busca do Google. \\
\hline 2. Estar nas primeiras páginas de busca do setor de atuação. & $\begin{array}{l}\text { É necessário digitar o nome completo do órgão ou PCN Brasil para aparecer na primeira } \\
\text { página, caso contrário aparece a sigla de Parâmetros Curriculares Nacionais, mais conhecida. }\end{array}$ \\
\hline 3. Velocidade de carregamento. & Muito boa, abaixo de dois segundos. \\
\hline 4. Layout/ apelo visual /equilíbrio entre gráficos e textos. & $\begin{array}{l}\text { Apresenta boa tipologia, mas não tem recursos visuais. Não tem elementos ilustrativos, além } \\
\text { de textuais. }\end{array}$ \\
\hline 5. Uso de recursos como vídeos e podcasts. & Um vídeo sobre o órgão (ver análise específica sobre o vídeo). Não estão incluídos podcasts. \\
\hline 6. Textos disponíveis em inglês. & $\begin{array}{l}\text { A mensagem inicial do texto informando sobre a modificação do atendimento durante a } \\
\text { pandemia, as Diretrizes e o Manual de Procedimentos para Instâncias Especificas/alegações } \\
\text { estão disponíveis, mas não os relatórios anuais e relatórios de encerramento das alegações. } \\
\text { Não existem textos em espanhol. }\end{array}$ \\
\hline $\begin{array}{l}\text { 7. Usabilidade: linguagem e posicionamento claro; botões e menus com } \\
\text { acessibilidade para smartphones. }\end{array}$ & $\begin{array}{l}\text { Linguagem textual técnica, o principal recurso para navegação é a barra de rolagem de } \\
\text { textos com links, grande parte deles indisponíveis. Alguns botões não funcionam. Pouca } \\
\text { adaptação para smarthphones, tornando difícil a leitura no aparelho. } 0 \text { site possui o recurso de } \\
\text { acessibilidade para deficientes auditivos em libras. }\end{array}$ \\
\hline $\begin{array}{l}\text { 8. Sistema eletrônico para inserção das alegações de inobservância } \\
\text { das Diretrizes. }\end{array}$ & $\begin{array}{l}\text { Indisponível, as alegações estão sendo feitas pelo e-mail <pcn.ocde@economia.gov.br> ou } \\
\text { pelo correio. }\end{array}$ \\
\hline 9. Métricas de quantidades de ações específicas por visitante. & Não disponível, em especial o número de visitantes da página. \\
\hline $\begin{array}{l}\text { 10. Uso de ferramentas do Google Analytics: origem do tráfego e metas, sem } \\
\text { rush, hashtag e endereços. }\end{array}$ & Informação não disponível. \\
\hline $\begin{array}{l}\text { 11. Uso da ferramenta Google Trends que permite a comparação com } \\
\text { palavras-chave utilizadas por organizações semelhantes. }\end{array}$ & Informação não disponível. \\
\hline 12. Avaliação das opções disponíveis para navegar no site. & $\begin{array}{l}\text { Poderia ter uma melhor disposição e arquitetura de informações (explicação sobre o PCN e } \\
\text { vídeo no início). Links importantes não funcionam. }\end{array}$ \\
\hline 13. Número de cliques para chegar onde se deseja. & São poucos, mas alguns links importantes não dão acesso à informação anunciada. \\
\hline $\begin{array}{l}\text { 14. Documentos relevantes que permitam a transparência e auditagem das } \\
\text { alegações aceitas. }\end{array}$ & $\begin{array}{l}\text { O link para o processo de consulta pública do manual de procedimentos não está disponível. As } \\
\text { declarações das instâncias específicas não estão disponíveis. }\end{array}$ \\
\hline $\begin{array}{l}\text { 15. Pesquisa de satisfação on-line após a visita do usuário sobre o canal } \\
\text { de comunicação e possíveis dificuldades, dúvidas, sugestões e grau de } \\
\text { confiança na agência. }\end{array}$ & Não é realizada. \\
\hline $\begin{array}{l}\text { 16. Autonomia da equipe do PCN para atualizações e organização de } \\
\text { informações no site. }\end{array}$ & Não há autonomia. \\
\hline 17. Seção de notícias/ divulgação/ assessoria de imprensa. & Não possui. \\
\hline
\end{tabular}

Elaboração da autora.

\subsubsection{Vídeo institucional}

O vídeo foi postado em 9 de dezembro de 2019 no canal do Ministério da Economia no YouTube e é bem realizado tecnicamente. Tem narração em off e cenas de bancos de imagens com executivos multiculturais e relativas à sustentabilidade, além de figuras que exemplificam didaticamente os conceitos e conteúdos e legendas em inglês. Tem 2 minutos e 21 segundos de duraçáo e pode ser acessado por meio de um link direto da página do PCN Brasil. O vídeo aborda as multinacionais e sua cadeia de fornecedores; a relaçáo com os Objetivos do Desenvolvimento Sustentável (ODS) promovido pela Organização das Nações Unidas (ONU); a estrutura; as denúncias sobre as violações das Diretrizes; e o PCN Brasil.

O final do vídeo pode confundir o espectador, já que o áudio de encerramento informa (entre 01:57 e 02:14): "A secretaria executiva da CAMEX, órgão integrante do Ministério da Economia e que tem trabalhado na disseminação do PCN para atrair investimentos qualificados e promover a inserção das empresas brasileiras no mercado externo. Mais informaçôes no site <www.pcn.economia. gov.br>.”. O lettering e o áudio informam o endereço eletrônico errado, não sendo possível acessar 
a página com esta direção. Ademais, pode-se, logicamente, inferir que o PCN possa contribuir para a inserção brasileira no mercado internacional, contudo essa não é sua principal função, mas da CAMEX. As assinaturas são do governo brasileiro/Ministério da Economia e ODS. Não estão disponíveis informaçóes sobre a produtora do vídeo.

Existem duas postagens do mesmo vídeo no YouTube. A segunda tem como título "OCDE e o Brasil", não se refere explicitamente ao PCN Brasil e surge como nono na lista de sugestôes do canal em buscas para a palavra-chave OCDE feitas a partir do Brasil. Quando digitada a expressão "Ponto de Contato Nacional”, o vídeo aparece em primeiro na lista, mas a informação é de que teve apenas 142 visualizaçóes desde a postagem (ocorrida em 2 de dezembro de 2019). Já o vídeo acessado a partir do link na página do PCN possui pouco mais de 1.300 visualizações (até meados de fevereiro de 2021), uma média de pouco mais de 100 visualizaçóes mensais desde que foi postado.

\subsubsection{Manual de Procedimentos para Instâncias Específicas}

Esse documento é extremamente importante, uma vez que versa sobre os processos e regras relativos às denúncias de empresas que violaram as Diretrizes. A OCDE recomenda que seja um documento elaborado por consulta pública e que esteja disponível on-line. O ideal é que o texto seja claro, didático e compreensível a uma variedade de partes alegantes (denunciantes) como indivíduos, sindicatos, ONGs, empresas e governos.

O Manual de Procedimentos para Instâncias Específicas está disponível nas versões inglês e português e pode ser baixado em PDF. ${ }^{21}$ Como anexo, está o Formulário para Submeter Instância Especifica ao Ponto de Contato Nacional, também em formato PDF (ou seja, não editável por usuários pouco familiarizados ao uso de ferramentas de edição), que precisa ser enviado para o órgão por e-mail ou por correio (existe um sistema eletrônico para envio direto das alegaçóes, mas encontra-se indisponível por problemas técnicos). Essa maneira, apesar de mais trabalhosa, é comumente adotada pelos PCNs, inclusive em países-membros da OCDE como França, Holanda e Itália.

O documento apresenta linguagem técnica, clara e concisa, e mostra detalhadamente todas as etapas do processo e os prazos. Conta com glossário e links para os documentos legais de normatização do PCN Brasil e assemelha-se à estrutura dos manuais de procedimentos de outros PCNs. Como sugestáo, poderia contar com figuras, ampliar os termos do glossário e trazer casos de alegaçóes concluídas como exemplos.

\subsubsection{Relatórios anuais}

Estão disponíveis em português três relatórios anuais de atividades para o Coninv, supervisor legal do PCN Brasil, para os anos de 2019 e 2020 (primeiro e segundo semestre). No documento constam as seguintes partes: contextualização, promoção de parcerias, mecanismo não judicial de solução de controvérsias (instâncias específicas), relacionamento com OCDE e coordenação de políticas de CER. Os documentos são sucintos, mas ilustrativos do imenso volume de atividades e trabalho realizado pelo PCN Brasil. Não apresentam informaçóes detalhadas sobre estrutura de recursos humanos e materiais do PCN, nem um balanço final sobre as atividades.

21. Disponível em: <https://www.gov.br/produtividade-e-comercio-exterior/pt-br/assuntos/camex/pcn/produtos/formularios/pcn-manual-deprocedimentos-para-instancias.pdf>. 
O relatório de 2020 está disponível no site desde a segunda quinzena de fevereiro de 2021 esse é um aspecto positivo do PCN Brasil na análise comparativa. Outros PCNs, inclusive de países desenvolvidos, nem sempre conseguem manter atualizadas as postagens de seus relatórios. O PCN francês disponibilizou somente até o ano de 2018 e os PCNs do Chile, Holanda e Itália disponibilizaram os relatórios até 2019.

Também estão disponíveis os relatórios para a OCDE desde o ano de 2013 até o primeiro semestre de 2020. Os documentos não são padronizados e variam muito em relação às informaçóes apresentadas. A maioria das informaçóes está em inglês e trata-se de formulário, criado pela OCDE.

\subsubsection{Desafios do PCN Brasil em relação à comunicação}

De acordo com informaçóes prestadas pela vice-coordenadora, a comunicação institucional do PCN Brasil não é feita por uma assessoria exclusiva do órgão. Assim, depreende-se que não há planejamento integrado e estratégico das açóes de comunicação (assessoria de imprensa, publicidade/marketing e relaçóes públicas).

O modelo criado por Kunsch (2003) é bastante instrumental, uma vez que alinha a comunicação aos objetivos estratégicos a serem atingidos pelas organizaçôes. Integra diferentes áreas da comunicação e administrativas, bem como contempla a diversidade e especificidades de públicos. A forma de atuação dos PCNs pressupóe o diálogo permanente e a junção entre objetivos organizacionais e comunicacionais bem como uma sintonia fina entre equipes de gestores técnicos e comunicacionais. Nesse sentido, a equipe técnica deve sempre pautar os temas mais importantes a serem destacados, com base no mandato, orientações da OCDE e particularidades das partes interessadas. Além disso, a comunicação deve pautar o PCN como um dos principais atores na implementação da CER das multinacionais.

Durante o período de coleta de dados não foi possível identificar notícias veiculadas nos meios de comunicação (imprensa, portais de notícia, rádio, televisão) sobre as atividades do PCN Brasil. As buscas foram realizadas na internet em janeiro de 2021, o que pode indicar problemas de visibilidade, divulgação e conhecimento do órgão pela imprensa e opinião pública.

As relações comunicativas acontecem num cenário dinâmico, complexo e multissistêmico de relacionamentos: com equipe técnica com representantes interministeriais, mediadores, alegantes, alegados, representantes de entidades empresariais, sindicatos, ONGs, mídia, diferentes setores do governo, rede dos PCNs, OECD Watch, OIT, BIAC, organizaçôes do Sistema Naçóes Unidas etc. Nesse sentido, é preciso definir uma política de comunicação que permita o cumprimento do mandato da agência, estabelecer e manter relações com as partes interessadas. O desafio é maior pelo fato de a agência fazer parte da estrutura de comunicação governamental e ter pouca autonomia para mudanças.

Os processos comunicacionais do PCN subordinam-se e fazem parte da estrutura de comunicação do governo brasileiro, em especial do Ministério da Economia. Tem, portanto, uma série de limitaçóes que são impostas pelo padrão da comunicação oficial, especialmente no que diz respeito aos sites públicos, um dos principais instrumentos de comunicaçáo das açóes governamentais. Isso, possivelmente, limita a autonomia de atualizaçôes e o provimento adequado de recursos orçamentários, materiais e humanos para realização de uma comunicação estratégica e integrada. O resultado é notavelmente sentido em relação à variedade dos recursos disponíveis e à qualidade da informaçáo disseminada. Há pequena potencialização dos instrumentos de comunicação, de forma diferente do que ocorre no setor empresarial e até de outras agências públicas brasileiras nos níveis federais, estaduais e municipais. 
As fragilidades da comunicação institucional foram exacerbadas com a fusão dos ministérios da Fazenda, do Planejamento e do Desenvolvimento, Indústria, Comércio Exterior e Serviços, o que resultou em um quadro de grande complexidade para o desenvolvimento de estratégias integradas de comunicação e grandes perdas informacionais e da memória institucional do órgáo. Esse contexto é resultante dos riscos inerentes à migração e à complexidade da organização de um grande volume de informaçóes de diferentes agências, da integração entre os diferentes canais comunicacionais do governo e da falta de capacitação das equipes de comunicação e tecnologia da informação em temas da CER e relativas às Diretrizes.

Diante deste quadro, pode-se inferir, portanto, que aumentaram as lacunas e a indefinição de responsabilidades na nova estrutura de comunicação ministerial e menor autonomia da equipe do PCN na coordenação da comunicação e na divulgação das atividades de promoção das Diretrizes. Nesse cenário, é importante definir uma política de comunicação e um planejamento integrado de comunicaçáo que contemple o mandato do PCN e aumente a efetividade para exercer suas funçóes de promover as Diretrizes, lidar com as alegaçóes e tratar de questóes de due diligence, o que implica dispor de instrumentos de comunicaçáo dialógicos e de qualidade.

\section{CONSIDERAÇÕES FINAIS}

Nosso objetivo foi verificar se os requisitos relativos às comunicaçóes previstos pelas Diretrizes da OCDE são atendidos pelo PCN Brasil e realizar uma análise qualitativa dos ICIs com vistas ao aprimoramento dos processos comunicacionais. Observamos que o PCN Brasil atende a maioria dos requisitos formais da OCDE em relação aos indicadores de avaliação das comunicaçóes. Entretanto, na análise qualitativa dos ICIs, verificou-se o escasso uso de recursos de atratividade, persuasão e dialogicidade. É necessário incrementar o site, principal meio de comunicação do PCN, para que a agência tenha maior visibilidade, reconhecimento e transparência em relação aos processos das alegaçôes e promova as Diretrizes da OCDE.

Dessa maneira, sugerimos o desenvolvimento de ações estratégicas e integradas de comunicação para a promoçáo da CER das multinacionais entre as partes interessadas. Destacamos a necessidade de implementar as estratégias comunicativas com a liderança e maior autonomia da equipe técnica para atualização e hierarquização das informaçóes na arquitetura do site. Propomos que o planejamento e a execução das açóes comunicacionais sejam desenvolvidos em sinergia com as áreas de comunicação e tecnologia da informação.

Entre as limitaçóes da pesquisa, destacamos que o estudo foi realizado tendo como base as referências dos indicadores de comunicaçôes elaborados OECD Watch e a análise dos instrumentos de comunicação do PCN Brasil. Uma abordagem mais completa, em estudos futuros, implicaria ouvir as partes interessadas buscando apreender as nuances e especificidades dos discursos e práticas comunicativas estabelecidas entre os públicos internos e externos e, principalmente, com as partes interessadas. 


\section{REFERÊNCIAS}

CÔRREA, E.S. Comunicação Digital e seus usos institucionais. In: KUNSCH, M. M. K. (Org). Gestão estratégica da comunicaçáo organizacional e relaçóes públicas. São Caetano: Difusão Editora, 2008.

DUARTE, J. Instrumentos de comunicação pública. In: . Comunicaçáo pública: Estado, mercado, sociedade e interesse público. São Paulo: Atlas, 2009.

KUNSCH, M. M. K. Planejamento de relaçóes públicas em comunicaçáo integrada. Sáo Paulo: Summus, 2003.

MATOS, H. A comunicação pública na perspectiva da teoria do reconhecimento. In: KUNSCH, M. M. K. Comunicaçáo pública, sociedade e cidadania. São Caetano do Sul: Difusão, 2011.

OECD - ORGANISATION FOR ECONOMIC CO-OPERATION AND DEVELOPMENT. Annual report on the OECD Guidelines for Multinational Enterprises 2018. Paris: OECD, 2019.

. Annual report on the OECD Guidelines for Multinational Enterprises 2019. Paris: OECD, 2020a.

National contact points for responsible business conduct. Paris: OECD, $2020 \mathrm{~b}$. 
